\title{
FOREWORD - SIGraDi
}

\author{
Dear SIGraDi and eCAADe colleagues,
}

Every year we make a great effort to bring together the members of our Ibero-American Society of Digital Graphics and every time it is a different team in Iberoamérica that takes the enormous commitment to organize our annual conference. Likewise, every year a growing number of members is joining the call to expand and renew our community, building a space to share experiences and ideas. The challenge of organizing the XXIII Congress was taken up by the Faculdade de Arquitectura de la Universidade do Porto, in Portugal, with its chairs, Gonçalo Castro Henriques, José Pedro Sousa, and João Pedro Xavier.

This year is without a doubt special for us, as for the first time in history we are holding a joint Congress of two sister societies in the CAAD field. This event marks a milestone in the development of our paths and opens the door to new ways of exchange and thinking. The idea of holding a joint congress between SIGraDi and eCAADe arises from the topographical. coincidence that occurs in Portugal, which in addition to obviously belonging to Europe, is also part of Iberoamérica, a category embracing all Spanish and Portuguese speaking countries in America plus the Iberian Peninsula (Portugal and Spain). This coincidence, however, was only a starting point, since it required a great deal of work on the part of the organizing committee and the teams designated by both steering committees. Today we can say that it was truly worth it and we can be proud of this historic achievement.

This year the conference motivates us to think and explore about "Architecture in the Age of the 4th Industrial Revolution", being a very suitable topic for our time. We are currently suffering rapid and fundamental transformations in the ways we manufacture, design and project, communicate with machines and cyber-physical systems, or with each other. This situation must be understood as a challenge to our collective future, a challenge of planetary scale. The era of the Anthropocene demands urgent solutions to problems created by ourselves. It is an urgent need to modify our practices, ways of living and ways of producing. This is everyone's responsibility, but fundamentally that of the decision-makers. 
Finally, it is very important to highlight the relevance of this gathering of continents and cultures in the current context, where the latent threat of xenophobia, discrimination, and nationalist fundamentalism becomes increasingly visible. Our meeting is therefore also a signal for the future that challenges the geopolitical order, as a message of intercultural coexistence, a plea for respect of differences, and for open and distributed knowledge.

Our both societies are sustained by a legacy of decades of effort, but above all, it is sustained by people and collectives embodying our common quests and interests. We are part of something bigger than ourselves, something that surpasses and expands us, but that depends on each and every member of the community. Years ago, we began a path full of curiosity, which makes us wait every year for this very moment of meeting and collective reflection, of reunion and celebration. Now we face challenges that we want to face together.

Rodrigo Martin-Iglesias,

President of SIGraDi 